\title{
Role of Autologous Fibula Strut Graft in Surgical Management of Tubercular Spondylitis by Anterior Approach: A Prospective Study
}

\author{
HEMANT BANSAL, MS, SAURABH SINGH, MS, MCH, SANJAY YADAV, MS, SAMRAT SAHOO, MS \\ Department of Orthopaedics, Institute of Medical Sciences, Banaras Hindu University, Varanasi, India
}

\begin{abstract}
Background: Decompression of cord in tubercular paraplegia is a mainstay treatment with favorable neurological improvement. Anterior decompression and stabilization with autologous bone grafts promotes fusion of affected segment of spine and prevents further progression of deformity. The objective of this study is to assess the role of autologous fibula strut graft in correction of tubercular kyphosis without instrumentation.

Methods: Twenty patients of tubercular spine (Gulhane Askeri Tip Akademisi type II or III) with paraplegia were treated with anterior decompression, debridement, and stabilization with various autologous bone graft in combination without instrumentation. Patients were further grouped as follows (10 in each group): group A includes patients where autologous fibula strut, rib, and iliac crest grafts were used in combination; group B includes patients where only autologous rib and iliac crest grafts were used. Results were analyzed in terms of neurological recovery (Frankel grade), graft union time (graft uptake), correction and progression of kyphotic deformity, and graft subsidence.

Results: Patients in both groups A and B show similar neurological recovery from Frankel grade A/B to E. Group A (fibula strut group) patients show mean correction of $6.7^{\circ}\left(3^{\circ}-22^{\circ}\right)$ in kyphosis with no loss of correction after a 2-year follow-up, whereas patients in group B (nonfibular strut group) show increase in kyphosis in immediate postoperative period without further progression on follow up. Graft uptake was good in all 19 cases, and graft subsidence was seen in 1 patient of group A.

Conclusions: Bone grafting is indispensable in surgical management of tubercular spine. It allows fusion of affected segment and prevents further progression of deformity. However, the neurological recovery of patient depends upon the adequate decompression of cord, debridement, and adequate stabilization of anterior and middle column vertebral body height loss. The use of autologous fibular strut graft along with cancellous graft is superior to only cancellous grafts in terms of kyphosis correction.
\end{abstract}

Other and Special Categories

Keywords: tubercular spondylitis, paraplegia, anterior decompression, fibula strut graft

\section{INTRODUCTION}

Management of tubercular spondylitis is not uniform throughout the world. ${ }^{1}$ Chemotherapy constitutes the main modality of treatment. It takes care of tubercular infection, but it cannot address the coexisting bone destruction, pre-existing and/or residual deformity, paraplegia, or pulmonary insufficiency due to spinal deformity.

Restoration of spinal stability is crucial in the management of spinal tuberculosis (TB) in many cases. Many times, kyphosis in spinal tuberculosis continues to progress with conservative treatment, and approximately $3 \%$ to $5 \%$ of cases will have severe progression. ${ }^{2}$
Evolution of surgical modalities in treatment of tubercular spine shows that anterior debridement along with use of autologous bone graft is the mainstay of treatment. With improvement in surgical skills and availability of various fixation instrumentation and demand for early rehabilitation of patient, the role of autologous bone grafts has been neglected.

Review of literature shows that many authors were using autologous rib graft post debridement to substitute the vertebral height loss and to augment fusion. Later owing to better osteoinductive, osteogenic, and biomechanical properties, iliac crest grafts were routinely used. On subsequent research and patient follow-up, progression of kyphosis and spinal instability due to graft subsidence or lysis 
brought the need for augmentation of bone graft with instrumentation to acutely correct the kyphosis and prevent its further progression.

For early rehabilitation program, aimed at shorter hospitalization and with intent to return the patient early to full-time work, it is essential to have stiff anterior construct with bone grafting and implants. The inconvenience with anterior approach are lack of adequate space to insert the anterior implants and the likely problem of prominent hardware putting pressure on the great vessels particularly in the thoracic spine. Further retrieval of dislodged anterior hardware is more dangerous, and fixation in cancellous vertebral bodies gives less pull-out strength compared with fixation in the dense pedicles. ${ }^{3}$

With the advancement and improvement in surgical skills, the role of various autologous bone grafts and their contribution in spinal stabilization have been under researched. This study is to assess the role of autologous fibula strut graft in stabilization of spinal segment following anterior debridement without any instrumentation in respect to kyphosis correction and neurological improvement.

\section{METHODS}

This is a prospective study conducted with prior approval from the institute's ethical committee, and the patients were randomly selected into the study. All patients were included in the study only after they were informed about the study, surgical treatment adopted, merits and demerits of surgery, and were asked to sign the designed consent form.

Patients admitted with tubercular spondylitis either not improving with appropriate antitubercular drugs and bed rest or their condition was deteriorating and patients who presented with early onset neurological deficit were studied. Patient population comprised 20 patients operated with anterior (transthoracic and retroperitoneal approach) debridement, spinal cord decompression, and stabilization with a combination of various autologous (fibula strut, iliac crest, rib graft) bone grafts without any instrumentation and were followed up to a minimum period of 2 years.

Based on the combination of grafts used, postoperatively patients were grouped as follows: group A, which includes patients where auto fibula strut, auto-rib, and auto iliac bone grafts were used, and group B, which includes patient where auto rib and auto iliac bone grafts were used. (Group B with comparatively less biomechanical strength of graft.)

Inclusion criteria were as follows: Patients of tubercular spine, type II and III as per Gulhane Askeri Tip Akademisi (GATA) classification ${ }^{4}$ (Figure 1), between 18 and 65 years of age. Patients of dorsal and dorsolumbar tubercular spine with active, wet lesions.

Exclusion criteria were as follows: Patients younger than 18 years and older than 65 years. Patients of tuberculosis of cervical, lower lumbar, lumbosacral spine, and multilevel tubercular spine.

Indications for surgery were neurological involvement in the form of paraplegia, which failed to respond to conservative therapy or failure of response after 4 to 6 weeks of nonoperative treatment and tubercular spine with GATA type II and III lesion.

Patients with neural deficits were graded according to the Frankel's scale. ${ }^{5}$ Radiological and magnetic resonance imaging (MRI) evaluation was done in all patients prior to surgery and level of involvement, and angle of local kyphosis was calculated. Local kyphosis was measured preoperatively, postoperatively, and at the 2- to 5-year follow-up visit. Vertebral collapse, destruction, and cold abscess were assessed in MRI.

All patients were operated with anterior approach in left lateral position, and thoracotomy was done corresponding to the kyphotic deformity. After thoracotomy, the left lung deflated to improve exposure and to avoid inadvertent injury to the lungs. The abscess was drained, and accessible neural decompression was done with debridement of the destroyed vertebrae with intervening disc tissue leaving only a shell of bone of the opposite cortex. Before inserting the strut graft slots are made in the proximal and the distal healthy vertebral body. Kyphosis was corrected manually by applying anterior pressure at its apex. ${ }^{6}$ When the pressure on the back of the spine is released, the fibula strut graft is locked in position. Remaining gap is filled with pieces of rib that was resected during exposure and supplemented by auto iliac bone graft. The lungs are inflated to check that no inadvertent pleural tear has been made before wound closure over a chest drain. In group B patients, only ribs and iliac crest grafts were used.

Postoperatively, patients were given brace support. Turning with support was allowed immediately postoperative day after removal of drain. 


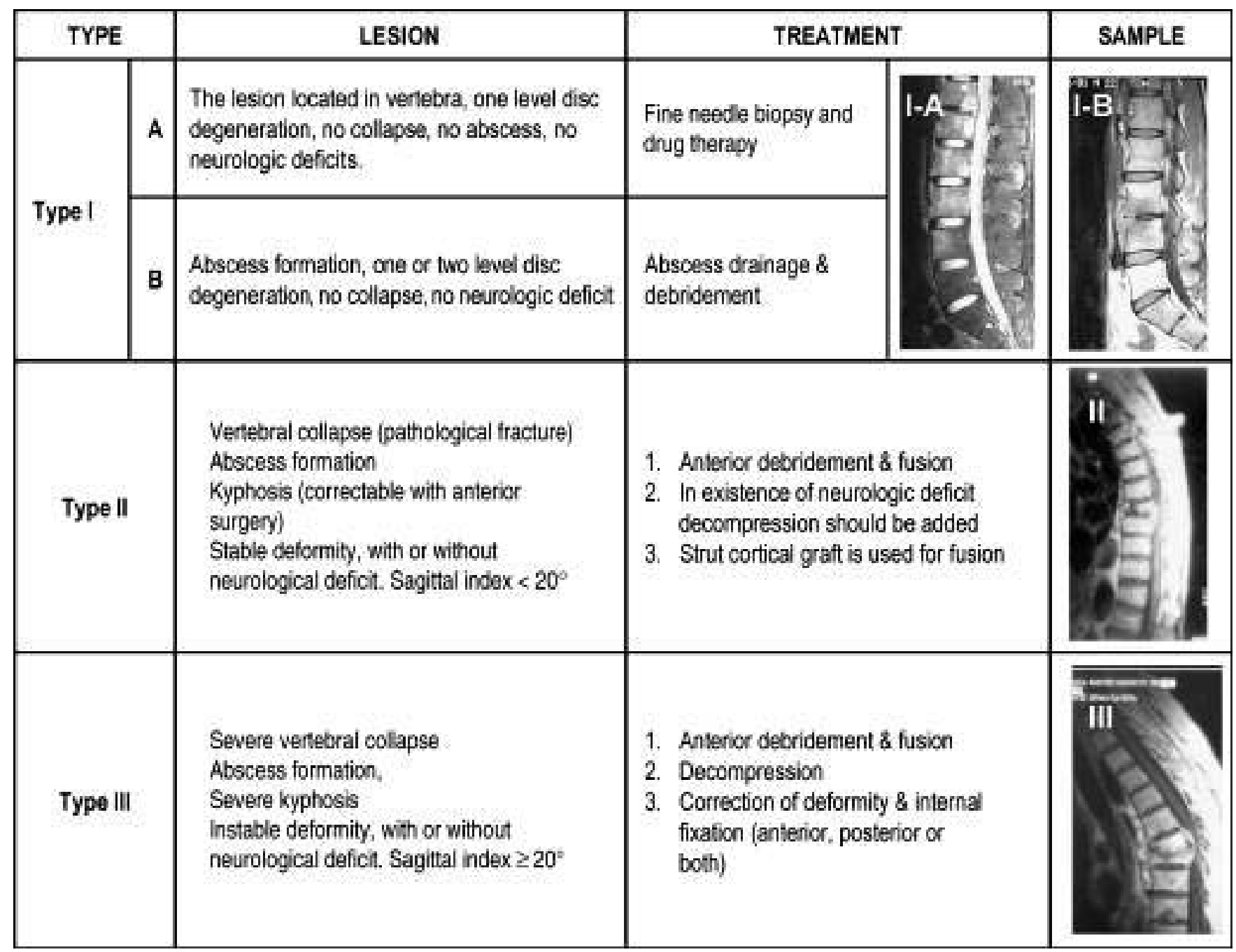

Figure 1. GATA classification of spinal tuberculosis.

Sitting with support was allowed after 6 weeks in group A and after 12 weeks in group B patients, and further standing and walking with support was allowed depending on neurological improvement and radiological assessment on regular follow-up.

Antitubercular therapy was given as per the World Health Organization guidelines without any default. Patients were regularly followed in an outdoor clinic every 3 months. On each follow-up, the patient's neurological status was assessed and postoperative rehabilitation was given.

Radiographically, bone graft was considered fused when there was appearance of bridging bony trabeculation through the graft with no radiolucency at graft vertebral interface. On dynamic radiograph, there should not be any movement between graft and the vertebral column. Graft subsidence was considered when graft breaks/fails or displaces from its place postoperatively or on follow-up course.

\section{RESULTS}

In this study, each group composed of 10 cases that were distributed among age, sex, vertebral level affected, no vertebrae involved, neurological status (Frankel grade) preoperatively and postoperatively, local kyphosis angle preoperatively and postoperatively, kyphosis correction, graft uptake, and subsidence (Tables 1 and 2).

In group $\mathrm{A}$, mean preoperative kyphosis of $31.5^{\circ}$ $\left( \pm 12.4^{\circ}\right)$ was seen, which was significantly corrected to mean postoperative kyphosis of $24.3^{\circ}$ $\left( \pm 14.8^{\circ}\right)$ with no loss of correction after 2 years of follow-up. Mean correction at 2-year follow-up: $6.7^{\circ}\left(3^{\circ}-22^{\circ}\right)$. 
Table 1. Distribution of cases in group A with outcome analysis.

\begin{tabular}{|c|c|c|c|c|c|c|c|c|c|c|c|c|}
\hline \multirow[b]{2}{*}{$\begin{array}{l}\text { Patient } \\
\text { No. }\end{array}$} & \multirow[b]{2}{*}{$\begin{array}{l}\text { Age } \\
(\mathrm{Y})\end{array}$} & \multirow[b]{2}{*}{ Sex } & \multirow[b]{2}{*}{$\begin{array}{l}\text { Vertebral } \\
\text { Level }\end{array}$} & \multirow[b]{2}{*}{$\begin{array}{l}\text { No. of } \\
\text { Vertebrae } \\
\text { Involved }\end{array}$} & \multicolumn{2}{|c|}{$\begin{array}{c}\text { Neurological Status } \\
\text { (Frankel Grade) }\end{array}$} & \multicolumn{4}{|c|}{ Kyphotic Deformity (Cobb's Angle) } & \multirow[b]{2}{*}{$\begin{array}{l}\text { Graft } \\
\text { Uptake }\end{array}$} & \multirow[b]{2}{*}{$\begin{array}{c}\text { Graft } \\
\text { Subsidence }\end{array}$} \\
\hline & & & & & Preoperation & $\begin{array}{c}\text { After } \\
\text { 2-Year } \\
\text { Follow-up }\end{array}$ & Preoperation & $\begin{array}{l}\text { Immediately } \\
\text { Postoperation }\end{array}$ & $\begin{array}{c}\text { After } \\
\text { 2-Year } \\
\text { Follow-up }\end{array}$ & $\begin{array}{l}\text { Kyphosis } \\
\text { Correction }\end{array}$ & & \\
\hline 1 & 22 & Female & D5-D6 & 2 & A & $\mathrm{E}$ & $38^{\circ}$ & $35^{\circ}$ & $35^{\circ}$ & $3^{\circ}$ & Yes & No \\
\hline 2 & 40 & Female & D6-D8 & 3 & B & $\mathrm{E}$ & $38^{\circ}$ & $33^{\circ}$ & $33^{\circ}$ & $5^{\circ}$ & Yes & No \\
\hline 3 & 40 & Male & D7-D8 & 2 & A & $\mathrm{E}$ & $20^{\circ}$ & $16^{\circ}$ & $16^{\circ}$ & $4^{\circ}$ & Yes & No \\
\hline 4 & 60 & Male & D9-D10 & 2 & A & E & $13^{\circ}$ & $4^{\circ}$ & $4^{\circ}$ & $9^{\circ}$ & Yes & No \\
\hline 5 & 30 & Male & D9-D10 & 2 & $\mathrm{~B}$ & $\mathrm{E}$ & $\mathbf{5 8}^{\text {oa }}$ & $5^{\circ}{ }^{\circ}$ & $5^{\circ}$ & $0^{\circ}$ & - & Yes \\
\hline 6 & 22 & Male & D9-D10 & 2 & A & $\mathrm{E}$ & $38^{\circ}$ & $32^{\circ}$ & $32^{\circ}$ & $6^{\circ}$ & Yes & No \\
\hline 7 & 55 & Male & D10-D12 & 3 & A & $\mathrm{E}$ & $24^{\circ}$ & $18^{\circ}$ & $18^{\circ}$ & $6^{\circ}$ & Yes & No \\
\hline 8 & 31 & Male & $\mathrm{D} 11-\mathrm{L} 1$ & 3 & A & $\mathrm{E}$ & $28^{\circ}$ & $16^{\circ}$ & $16^{\circ}$ & $12^{\circ}$ & Yes & No \\
\hline 9 & 30 & Male & D11-L1 & 3 & $\mathrm{~B}$ & $\mathrm{E}$ & $32^{\circ}$ & $28^{\circ}$ & $28^{\circ}$ & $4^{\circ}$ & Yes & No \\
\hline 10 & 30 & Female & $\mathrm{D} 12-\mathrm{L} 1$ & 2 & A & $\mathrm{E}$ & $26^{\circ}$ & $18^{\circ}$ & $18^{\circ}$ & $8^{\circ}$ & Yes & No \\
\hline
\end{tabular}

${ }^{\mathrm{a} B o l d}$ indicates graft subsidence.

In group $\mathrm{B}$, mean preoperative kyphosis of $27^{\circ}$ $\left( \pm 17.6^{\circ}\right)$ was seen, which shows deterioration to mean postoperative kyphosis to $30^{\circ}\left( \pm 11.5^{\circ}\right)$. Mean deterioration in kyphosis at immediate postoperative day: $5.7^{\circ}\left(2^{\circ}-14^{\circ}\right)$ with no significant further progression at 2-year follow-up (Figure 2).

Overall postoperative correction in group A shows median correction of $5.5^{\circ}$, whereas group B shows deterioration of $4^{\circ}$ (Table 3 ).

In group $\mathrm{A}$, there was no loss of kyphotic correction at minimum 2-year follow-up, except in patient number 5 where, due to graft subsidence, progression of $5^{\circ}$ in kyphotic deformity was seen (Figure 3).

In group B, deterioration in kyphosis was seen in all patients at immediate postoperative day except for patient number 3 where at immediate postoperative day, correction of $18^{\circ}$ in kyphosis was seen, which at 2-year follow-up shows $12^{\circ}$ loss of correction (Figure 4).

There was no difference in neurological recovery in both groups, and all patients showed significant improvement. At 2 years of follow-up, group A cases have advantageous mean kyphosis correction of $12.4^{\circ}\left(6.7^{\circ}+5.7^{\circ}\right)$ as compared with group B cases.

The 2 groups (A and B) were matched and found similar according to age (mean 36 vs 33.2 years), sex male-to-female ( $3: 7$ vs $4: 6$ ), average number of involved levels (2.5 vs 2.5), location of involved levels, severity of deformity $\left(31.5^{\circ}\right.$ vs $\left.27.0^{\circ}\right)$, and neurological status. The most common involved vertebral level in both groups was D8-L1 spine. Statistical test of significance used was the Student $t$ test and Mann-Whitney $U$ test.

Neurological improvement was equal in both groups. However, improvement in local kyphosis was significantly better in the fibular strut graft group (group A) $(P=0.001)$ with no loss of correction at 2 years of follow-up.

\section{DISCUSSION}

Spinal tuberculosis is the most common affection of osteoarticular tuberculosis. Neurological compli-

Table 2. Distribution of cases in group B with outcome analysis.

\begin{tabular}{|c|c|c|c|c|c|c|c|c|c|c|c|c|}
\hline \multirow[b]{2}{*}{$\begin{array}{l}\text { Patient } \\
\text { No. }\end{array}$} & \multirow[b]{2}{*}{$\begin{array}{l}\text { Age } \\
(\mathbf{Y})\end{array}$} & \multirow[b]{2}{*}{ Sex } & \multirow[b]{2}{*}{$\begin{array}{c}\text { Vertebral } \\
\text { Level }\end{array}$} & \multirow[b]{2}{*}{$\begin{array}{c}\text { No. of } \\
\text { Vertebrae } \\
\text { Involved }\end{array}$} & \multicolumn{2}{|c|}{$\begin{array}{l}\text { Neurological Status } \\
\text { (Frankel Grade) }\end{array}$} & \multicolumn{4}{|c|}{ Kyphotic Deformity (Cobb's Angle) } & \multirow[b]{2}{*}{$\begin{array}{c}\text { Graft } \\
\text { Uptake }\end{array}$} & \multirow[b]{2}{*}{$\begin{array}{c}\text { Graft } \\
\text { Subsidence }\end{array}$} \\
\hline & & & & & Preoperation & $\begin{array}{c}\text { After } \\
\text { 2-Year } \\
\text { Follow-up }\end{array}$ & Preoperation & $\begin{array}{c}\text { Immediately } \\
\text { Postoperation }\end{array}$ & $\begin{array}{c}\text { After } \\
\text { 2-Year } \\
\text { Follow-up }\end{array}$ & $\begin{array}{l}\text { Kyphosis } \\
\text { Correction }\end{array}$ & & \\
\hline 1 & 29 & Male & D2-D4 & 3 & $\mathrm{~B}$ & $\mathrm{E}$ & $24^{\circ}$ & $28^{\circ}$ & $28^{\circ}$ & $-4^{\circ}$ & Yes & No \\
\hline 2 & 30 & Female & D4-D5 & 2 & $\mathrm{~A}$ & $\mathrm{E}$ & $32^{\circ}$ & $36^{\circ}$ & $36^{\circ}$ & $-4^{\circ}$ & Yes & No \\
\hline 3 & 18 & Male & D4-D6 & 3 & A & $\mathrm{E}$ & $74^{\circ}$ & $56^{\circ}$ & $68^{\circ}$ & $6^{\circ}$ & - & Yes \\
\hline 4 & 18 & Female & D5-D6 & 2 & $\mathrm{~B}$ & $\mathrm{E}$ & $18^{\circ}$ & $26^{\circ}$ & $26^{\circ}$ & $-8^{\circ}$ & Yes & No \\
\hline 5 & 50 & Female & D6-D7 & 2 & $\mathrm{~A}$ & $\mathrm{E}$ & $26^{\circ}$ & $28^{\circ}$ & $28^{\circ}$ & $-2^{\circ}$ & Yes & No \\
\hline 6 & 50 & Male & D8-D9 & 2 & A & $\mathrm{E}$ & $10^{\circ}$ & $18^{\circ}$ & $18^{\circ}$ & $-8^{\circ}$ & Yes & No \\
\hline 7 & 56 & Male & D8-D9 & 2 & B & $\mathrm{E}$ & $14^{\circ}$ & $16^{\circ}$ & $16^{\circ}$ & $-2^{\circ}$ & Yes & No \\
\hline 8 & 20 & Female & D9-D11 & 3 & B & $\mathrm{E}$ & $26^{\circ}$ & $40^{\circ}$ & $40^{\circ}$ & $-14^{\circ}$ & Yes & No \\
\hline 9 & 26 & Male & D10-D11 & 2 & A & $\mathrm{E}$ & $22^{\circ}$ & $26^{\circ}$ & $26^{\circ}$ & $-4^{\circ}$ & Yes & No \\
\hline 10 & 35 & Male & D11-L1 & 3 & $\mathrm{~A}$ & $\mathrm{E}$ & $24^{\circ}$ & $26^{\circ}$ & $26^{\circ}$ & $-2^{\circ}$ & Yes & No \\
\hline
\end{tabular}




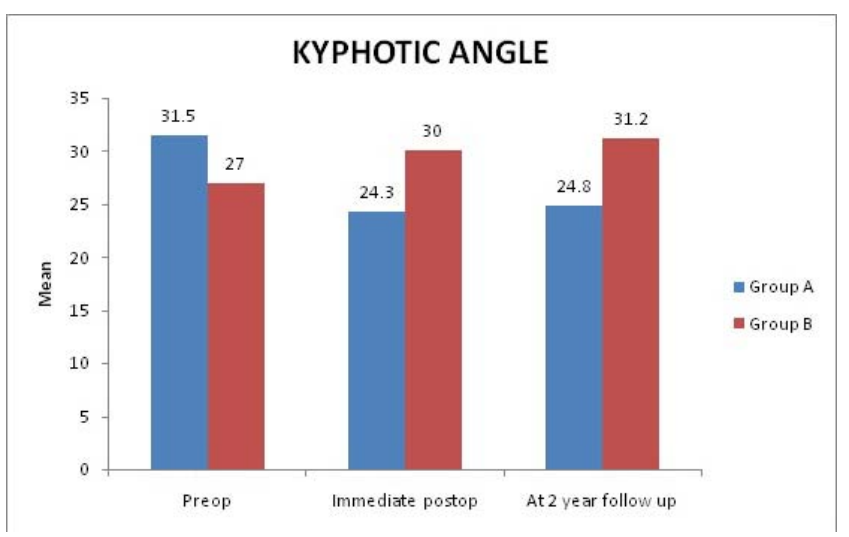

Figure 2. Depicting local kyphotic angle distribution in each group.

cations like paraplegia and quadriplegia along with deformity are the most debilitating complications of spinal tuberculosis. ${ }^{7}$ With the availability of better spinal stabilization options and surgical techniques, one should aim to achieve healed status of spinal tuberculosis with minimum or no deformity. Despite the advancement in medical treatment to control the disease, failure can occur in many cases because of osteolytic process of the disease as a result of which kyphosis develops. ${ }^{8}$

Many types of surgical approach have been described for debridement of tubercular spine, but it is rather difficult to strictly compare the results of
Table 3. Median kyphosis correction after 2-year follow-up.

\begin{tabular}{lcc}
\hline Group & Median (Interquartile Range) & $\begin{array}{c}\text { Mann-Whitney } \\
\boldsymbol{U} \text { test }(\boldsymbol{P} \text { Value) }\end{array}$ \\
\hline Group A & $5.50(3.75$ to 8.25$)$ & 0.001 \\
Group B & $-4.0(-8.0$ to -2.0$)$ & \\
\hline
\end{tabular}

various approaches and choice of approach varies from center to center.

In 1960, when the surgical treatment of spinal tuberculosis was still controversial, Hodgson and Stock ${ }^{9}$ described the routine use of debridement via the anterior approach, with a $93 \%$ fusion rate. In 1961, the French Society for Orthopaedic Surgery and Traumatology (SOFCOT) emphasized the predominant role for medical treatment while acknowledging the existence of 2 strategies, namely, routine local surgery and medical treatment alone with 4 antituberculosis drugs and a brace. ${ }^{10}$ However, published studies indicate widespread use of combined medical and surgical treatment; thus, in a review of case-series published between 1980 and 2011, surgery was performed in $75 \%$ of patients. ${ }^{11}$ At present, the need for surgery is recognized $^{12,13}$ in patients with evidence of spinal cord or nerve root compression, extensive abscess formation, spinal instability due to osteolysis with kyphosis, and failure of medical treatment.

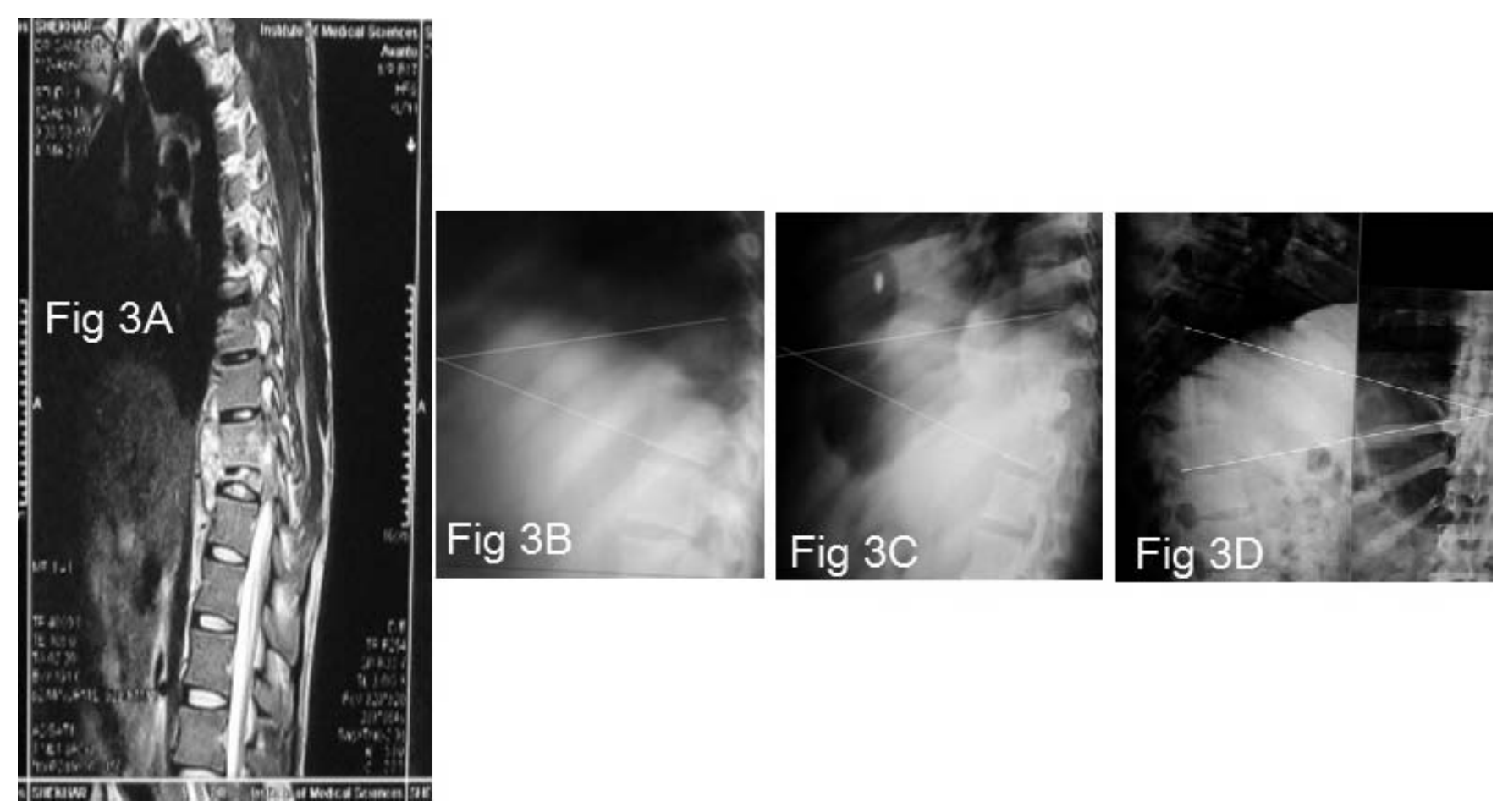

Figure 3. Patient number 6 (group A): a 22-year-old male with tubercular spine affecting D9-D10 vertebrae with paraplegia. (A) MRI showing involvement of D9-D10 vertebrae with prevertebral abscess. (B) Preoperative local kyphosis, $38^{\circ}$. (C) Immediate postoperative kyphosis, $32^{\circ}$. (D) Kyphosis at 2 years of follow-up, $32^{\circ}$. 


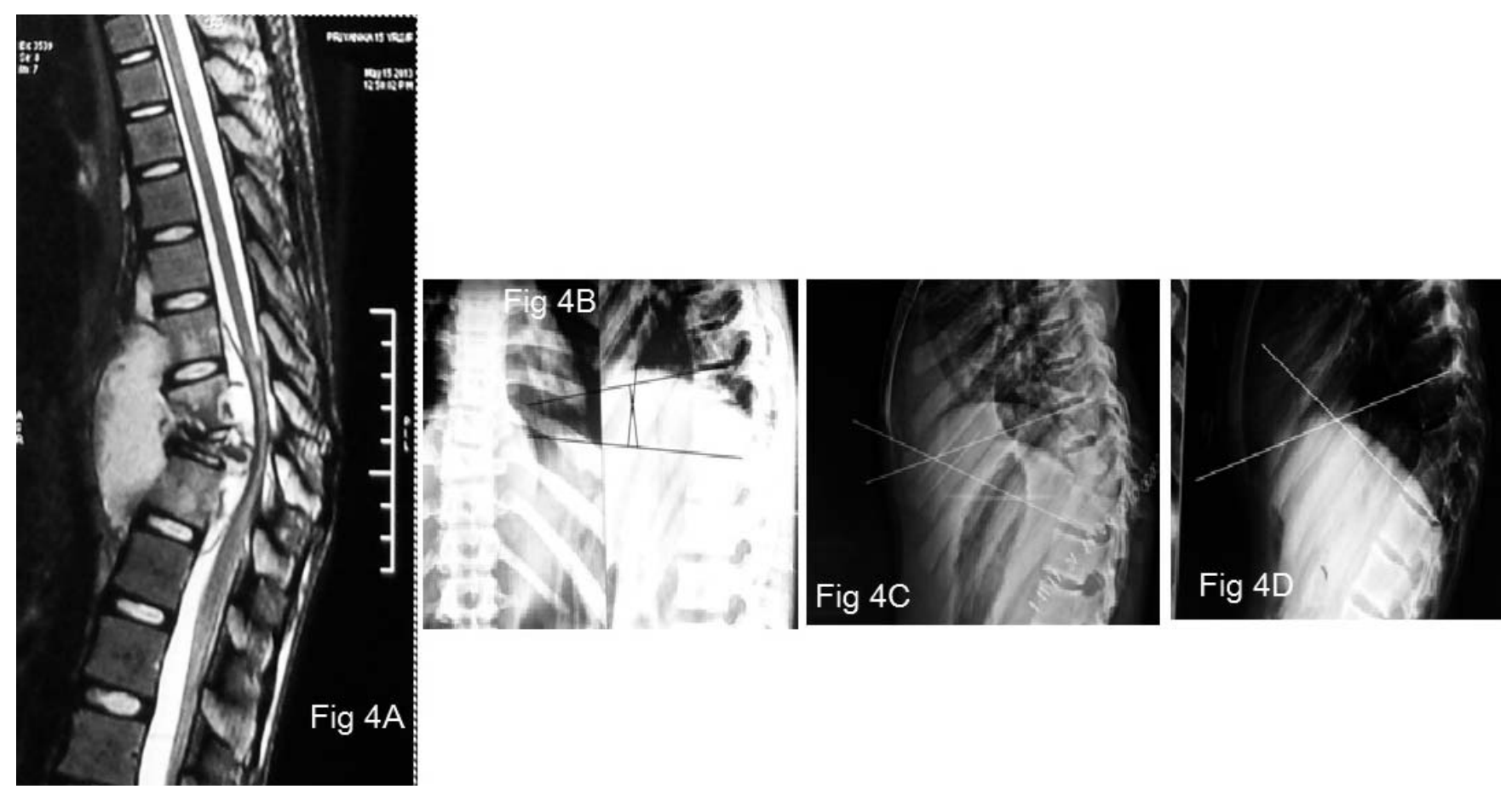

Figure 4. Patient number 8 (group B): a 20-year-old female with tubercular spine affecting D9-D11 vertebrae with paraplegia. (A) MRI showing involvement of D9D11 vertebrae with prevertebral abscess. (B) Preoperative local kyphosis, $26^{\circ}$. (C) Immediate postoperative kyphosis, $40^{\circ}$. (D) Kyphosis at 2 years of follow-up, $40^{\circ}$.

In patients with extensive abscess formation, the anterior approach remains the reference standard. ${ }^{14,15}$ This approach allows direct debridement of the prevertebral and intraspinal focus of infection. Pharmacokinetic studies have established that surgery improves the effectiveness of antituberculosis drugs when debridement is optimal. ${ }^{16}$ In addition, same-stage anterior grafting plays a key role in filling the lytic defect and strengthening the anterior column. ${ }^{17}$

The surgical management of typical spinal tuberculosis rests on 2 principles: debridement with spinal cord decompression and stabilization of the spine. These principles are also followed in some developing countries, where surgical treatment can prevent the long-term development of severe kyphosis. $^{18}$

Radical debridement with anterior approach and anterior fusion along with anterior strut grafts has come up in a big way in management of tubercular spondylitis in the present era. As most of the spinal cord compression is usually located anterior, anterior approach and decompression is the preferred route for neural decompression. ${ }^{19}$

There are many studies in the literature that have demonstrated satisfactory results by anterior instrumentation providing several advantages. ${ }^{1,20-22}$ Jain et $\mathrm{al}^{8}$ analyzed all articles in which instrumented stabilization was reported over the last 20 years. When anterior instrumentation $(\mathrm{n}=635)$ was used in tuberculous spondylitis, mean preoperative kyphosis was $25.35^{\circ}$, immediate postoperative kyphosis was $9.08^{\circ}$, and final kyphosis was $12.97^{\circ}$. There was an overall $2.3^{\circ}$ kyphosis progression after surgery.

Singh et $\mathrm{al}^{22}$ shows that the mean local kyphosis correction in the immediate postoperative period was $24.1^{\circ}$ in the instrumented group and was $6.1^{\circ}$ in the noninstrumented group. The mean late loss of correction of local kyphosis at 3 years' follow-up was $1.7^{\circ}$ in the instrumented and $6.7^{\circ}$ in the noninstrumented group.

The strength of our study is that a minimum period of 2 years' follow-up has been done for all the patients. The immediate postoperative local kyphosis correction in group A has been statistically significantly $(P<0.05)$ as compared with group $\mathrm{B}$, where deterioration in local kyphosis was seen in immediate postoperative kyphosis. However, there has been no statistical difference between groups A and $\mathrm{B}$ in terms of neurological improvement. There was neither significant loss of correction in local kyphosis at 2 years of follow-up in group A nor further deterioration in local kyphosis in group B. This differs from the observation of Singh et $\mathrm{al}^{22}$ study where the noninstrumented group showed 
mean late loss of local kyphosis correction of $6.7^{\circ}$. After analyzing the data of Singh et $\mathrm{al}^{22}$, it was found that the possible reason for late loss of local kyphosis correction in their noninstrumented group could be following: (1) inadequate use of properties of various autologous bone grafts. ${ }^{23}$ They used osteoconductive auto fibular graft for anterior fusion having minimal or no osteogenetic potential, leading to delayed graft uptake or graft subsidence on follow-up; (2) all cases included in study were of GATA type III category and carry higher magnitude of spinal instability with sagittal index $>20$, which requires additional instrumentation along with bone grafting following debridement.

Whereas in this study, we have prevented late loss of kyphotic correction by: (1) using osteogenetic, osteoinductive properties of auto iliac and auto rib grafts along with osteoconductive auto fibular strut bone graft; (2) in this study 18 out of 20 cases belong to GATA type II category and show $100 \%$ graft uptake without any subsidence. Oguz et $\mathrm{al}^{4}$ states that GATA type II category patients carry less spinal stability with sagittal index $<20$ and are well treated with anterior decompression and bone grafting; (3) in this study, 2 patients were of GATA type III category, which shows graft subsidence with delayed graft uptake resulted in late loss of local kyphosis correction on follow-up.

Thus, from this study in operative treatment of tubercular spondylitis, it is advisable to utilize the mechanical strength of fibula strut along with cancellous bone grafts to support the affected segment and also to correct local kyphosis to possible extent without further progression of deformity.

Addition of anterior instrumentation may improve the correction of local kyphosis and provide early rehabilitation of the patient. The correction of local kyphosis in the instrumented group is more perhaps due to the rigid nature of screws and rods that do not allow loss of correction in kyphosis achieved after corpectomy and manual anterior directed pressure on the apex of deformed tubercular gibbus spine.

Without the use of instrumentation, anterior debridement, decompression of cord, and autologous bone grafting are also associated with complete neurological recovery at 2 to 5 years' follow-up. However, the patients have to be confined to bed for a longer period of time, and local kyphosis would be more if anterior instrumentation were not used. The comparable neurological results in the above groups, despite different degree of kyphosis, can be ascribed to the fact that all the patients were of early onset paraplegia (duration from onset of symptoms to progression to paraparesis/plegia is less than 2 years). Underlying pathology in most cases is inflammatory edema, tuberculous abscess, and tuberculous caseous tissue. Thus, a thorough debridement of all infective tissues ensures adequate decompression of cord and hence the degree of local kyphosis does not correlate with the amount of neurological recovery in early onset paraplegia.

The belief that debridement of tubercular spondylitis lesion further destabilizes the spinal column and should always be combined with spinal instrumentation is not a compulsion as far as neurological recovery is concerned.

Morbidities due to prolonged immobilization, decreased correction of kyphosis in immediate postoperative period, and further progression of kyphosis in due course of time are well known disadvantages of not using spinal instrumentation after debridement. However, in cases with GATA type II lesion with relatively less osteolysis and spinal instability where instrumentation is not mandatory, comparable neurological results can be achieved with thorough anterior debridement, spinal cord decompression, and autologous bone grafting alone if adequate duration of immobilization, orthotic support, and antitubercular drugs are given.

\section{CONCLUSIONS}

Bone grafting is indispensable in surgical management of tubercular spine. It allows fusion of affected segment and prevents further progression of deformity. However, the neurological recovery of the patient depends upon the adequate decompression of cord, debridement, and adequate stabilization of anterior and middle column vertebral body height loss. The use of autologous fibular strut graft along with cancellous graft is superior to use of only cancellous grafts in terms of kyphosis correction.

\section{REFERENCES}

1. Ozdemir HM, Us AK, Ogun T. The role of anterior spinal instrumentation and allograft fibula for the treatment of pott disease. Spine. 2003;28(5):474-479.

2. Rajasekaran S, Shanmugasundaram TK. Prediction of the angle of gibbus deformity in tuberculosis of the spine. $J$ Bone Joint Surg. 1987;69:503-509. 
3. Chen CL, Chou CW, Su WW, Cheng CY, Yu CT. Dislodged upper thoracic cage in the gastrointestinal tract: a case report and literature reviews. Spine (Phila Pa 1976). 2008;33:e802-e806.

4. Oguz E, Sehirlioglu A, Altinmakas M, et al. A new classification and guide for surgical treatment of spinal tuberculosis. Int Orthop. 2008;32:127-133.

5. Frankel HL, Hancock DO, Hyslop G, et al. The value of postural reduction in the initial management of closed injuries of the spine with paraplegia and tetraplegia. I. Paraplegia. 1969; 7:179-192.

6. Jain AK, Aagarwal A, Dhami IK, Agarwal PK, Singh S. Extrapleural anterolateral decompression in tuberculosis of the dorsal spine. J Bone Joint Surg. 2004;86-b:1027-1031.

7. Jain AK. Treatment of tuberculosis of the spine with neurologic complications. Clin Orthop Relat Res. 2002;(398):7584.

8. Jain AK, Dhammi IK, Jain S, Mishra P. Kyphosis in spinal tuberculosis: prevention and correction. Indian J Orthop. 2010;44:127-136.

9. Hodgson AR, Stock FE. Anterior spinal fusion for the treatment of tuberculosis of the spine. J Bone Joint Surg. 1960;42a:295-310.

10. Symposium de la SOFCOT sur le mal de pott, 1961, direction J. Debeyre. www.aott.org.tr. Accessed August 15, 2012. [In French]

11. Fuentes Ferrer M, Gutiérrez Torres L, Ayala Ramírez O Rumayor Zarzuelo M del Prado González N. Tuberculosis of the spine. A systematic review of case series. Int Orthop. 2012;36:221-231.

12. Guerado E, Cervan AM. Surgical treatment of spondylodiscitis. An update. Int Orthop. 2012;36:413-420.

13. Mak KC, Cheung KMC. Surgical treatment of acute TB spondylitis: indications and outcomes. Eur Spine J. 2013;22(suppl 4):603-611.

14. Kapoor S, Kapoor S, Agrawal M, Aggarwal P, Jain BK Jr. Thoracoscopic decompression in pott's spine and its longterm follow-up. Int Orthop. 2012;36:331-337.

15. Li M, Du J, Meng H, Wang Z, Luo Z. One-stage surgical management for thoracic tuberculosis by anterior debridement, decompression and autogenous rib grafts, and instrumentation. Spine J. 2011;11:726-733.

16. Ge Z, Wang Z, Wei M. Measurement of the concentration of three anti-tuberculosis drugs in the focus of spinal tuberculosis. Eur Spine J. 2008;17:1482-1487.
17. Zhang HQ, Guo CF, Xiao XG, Long WR, Deng ZS, Chen J. One-stage surgical management for multilevel tuberculous spondylitis of the upper thoracic region by anterior decompression, strut autografting, posterior instrumentation, and fusion. J Spinal Disord Technol. 2007;20(4):263-267.

18. Djientcheu VP, Tambo FFM, Ndougsa IS, et al. The role of surgery in the management of Pott's disease in Yaoundé. A review of 43 cases. Orthoptraumatol Surg Res. 2013;99:419-423.

19. Aksoy MC, Acaroglu RE, Tokgozoglu AM, Ozdemir N, Surat A. Retrospective evaluation of treatment methods in tuberculosis spondylitis. Hacettepe J Orthopsurg. 1995;5:207209.

20. Benli I, Acaroglu E, Akalin S, Kis M, Duman E, Un A. Anterior radical debridement and anterior instrumentation in tuberculosis spondylitis. Eur Spine J. 2003;12(2):224-234.

21. Benli I, Kis M, Akalin S, Citak M, Kanevetci S, Duman E. The results of anterior radical debridement and anterior instrumentation in pott's disease and comparison with other surgical techniques. Kobe J Med Sci. 2000;46:39-68.

22. Singh S, Kumaraswamy V, Sharma N, Saraf SK, Khare GN. Evaluation of role of anterior debridement and decompression of spinal cord and instrumentation in treatment of tubercular spondylitis. Asian Spine J. 2012;6(3):183-193.

23. Pape HC, Evans A, Kobbe P. Autologous bone graft: properties and techniques. J Orthop Trauma. 2010;24(suppl 1):S36-S40.

Disclosures and COI: The authors received no funding for this study and report no conflicts of interest.

Corresponding Author: Hemant Bansal, MS, Department of Orthopaedics, IMS, BHU, Varanasi221005. Phone: (91) 775-494-1772; Email: hemant. 21bansal@gmail.com.

Published 31 October 2019

This manuscript is generously published free of charge by ISASS, the International Society for the Advancement of Spine Surgery. Copyright (C) 2019 ISASS. To see more or order reprints or permissions, see http://ijssurgery.com. 